Brit. J. industr. Med., 1959, 16, 153.

\title{
THE MECHANICAL PROPERTIES OF THE LUNG IN PNEUMOCONIOSIS OF COAL-MINERS*
}

\author{
BY \\ G. L. LEATHART
}

From the Nuffield Department of Industrial Health, King's College, Newcastle upon Tyne, University of Durham

(RECEIVED FOR PUBLICATION SEPTEMBER 1, 1958)

To assess changes in the mechanical properties of the lungs in pneumoconiosis, the "elastance" (coefficient of elastic resistance, the reciprocal of compliance) of the lung and resistance of the airways were measured by the method of Mead and Whittenberger (1953) in 97 coal-miners and 17 men who had never worked underground. Ages ranged from 24 to 57. The work done on the lung was measured in 66 of these subjects, and the maximum voluntary ventilation (M.V.V.) was measured in all. The subjects were obtained by random selection from hospital out-patients and by random selection from a radiological survey of over 5,000 coalminers. The M.V.V. was reduced in coal-miners with progressive massive fibrosis (P.M.F.), and in those without pneumoconiosis, but was not significantly reduced in simple pneumoconiosis. Elastance of the lung was unaltered in young miners but was slightly, and significantly, increased in all elderly faceworkers whatever the radiological category. This change appeared to be due to long years of work underground rather than to the radiological abnormality of pneumoconiosis. This slight change in the pulmonary elastance cannot be the cause of the reduction in M.V.V., since the two are unrelated. Inspiratory resistance was normal in all coal-miners, suggesting that pneumoconiosis is not associated with any fixed distortion of the airways. The non-elastic work of breathing, however, was frequently above normal and this suggests that bronchial obstruction develops rather commonly during expiration. This change appears to be the cause of reduction of M.V.V. in the majority of cases, as a negative correlation between M.V.V. and non-elastic work was established. Mean non-elastic work was not, however, unduly high in those radiological groups in which a significant reduction of M.V.V. was recorded. It is suggested that this discrepancy may be due to excessive frictional resistance in the chest wall of miners with P.M.F. and those with no radiological abnormality. The findings are consistent with the hypothesis that emphysema is abnormally common in elderly coal-miners, and that it, rather than pneumoconiosis, is the cause of their reduced ventilatory ability.

A great deal of work has been done to establish the cause of dyspnoea in coal-miners and its relationship to pneumoconiosis. This has been reviewed by Gilson and Hugh-Jones (1955) who themselves carried out a comprehensive series of pulmonary function tests on a group of miners and normal controls. It has been shown that there is a reduction of ventilatory capacity in coal workers with pneumoconiosis, especially when progressive massive fibrosis is present. On the other hand Carpenter, Cochrane, Gilson, and Higgins (1956) found that, in a random sample of a population, the ventilatory capacity of miners without pneumoconiosis was

*The results of this investigation were presented briefly at the Twelfth International Congress on Occupational Health, Helsinki, July, 1957. more severely restricted than that of miners with simple pneumoconiosis. This suggests that the dyspnoea which afflicts miners may be due to something other than simple pneumoconiosis. Moreover, Newell and Browne (1955) were unable to find any correlation between respiratory disability and simple pneumoconiosis in a large series of working miners.

There are two ways in which pneumoconiosis might reduce ventilatory capacity. The large fibrotic masses which develop in the lungs of an advanced case of pneumoconiosis undoubtedly cause compression or kinking of the bronchi in some cases, and thus increase the resistance of the airways. Obstruction of the airways can also occur without fibrosis, as in asthma. Secondly, the fibrous tissue itself probably makes the lungs stiffer than normal. Both 
these changes would tend to lower the ventilatory capacity and to cause dyspnoea. Measurement of these two factors might help to increase our understanding of the dyspnoea of coal-miners. It should establish whether there is any significant stiffness of the lungs or obstruction of the airways in simple pneumoconiosis and should confirm that it is present in P.M.F. In particular it might offer some explanation for the low ventilatory capacity of coal-miners without pneumoconiosis.

This paper presents the results of the determination of elastance and total non-elastic resistance (sum of airway and pulmonary viscous resistance) in a series of 105 miners and 10 controls. Maximum voluntary ventilation was also measured in these subjects.

\section{Methods}

A pilot study was done on a group of hospital patients and then an older group, chosen at random from a selected mining population, was investigated.

The hospital patients were aged 24 to 48 years (mean age 39 years) and included 37 coal-miners and 10 controls who were not miners. None of the patients was in need of medical treatment at the time of investigation and they were chosen at random from the out-patient files of the Nuffield Department of Industrial Health in the University of Durham, England. None of the control cases had any respiratory symptoms, and not one of them was investigated until 18 months had elapsed since his first hospital attendance.

The majority of the control cases were people who were thought to have undergone the risk of industrial poisoning, but were found to be normal. The diagnoses are given in Table 1. The four men who had been exposed to vanadium had all changed their work two years before investigation. If this exposure had left any residual damage, of which there were neither signs nor symptoms, this would tend to decrease the differences between the subjects and the controls, rather than to exaggerate them.

TABLE 1

DIAGNOSIS OF NON-MINING CONTROLS

\begin{tabular}{c|l|l}
\hline Age & \multicolumn{1}{|c|}{ Occupation } & \multicolumn{1}{c}{ Diagnosis } \\
\hline 24 & Fitter-heavy engineering & Exposed to vanadium \\
29 & Plant mechanic & Exposed to vanadium \\
31 & Fitter-heavy engineering & Exposed to vanadium \\
33 & Labourer-road works & Idiopathic epilepsy \\
34 & Charge hand-rubber factory & Exposed to CHCl:CCl \\
35 & Physician & Bornholm disease \\
36 & Lead furnace man & No abnormality \\
38 & Millwright & Exposed to vanadium \\
38 & Charge hand-zirconium plant & No abnormality \\
39 & Labourer in lead works & No abnormality \\
\hline
\end{tabular}

The other group, consisting of 68 coal-miners, aged 52 to 57 years (mean age 54), were selected at random from among those men of this age whose chest radiographs had been classified during a survey of four Durham coal-mines in 1950-51. The size of the sample, of the population from which it was drawn, and the number of men who actually completed the tests are shown in Table 2.

TABLE 2

SAMPLE OF COAL-MINERS (AGE 52-57)

\begin{tabular}{l|r|r|r|r}
\hline Radiological category & 0 & $1+2$ & 3 & P.M.F. \\
Number of men aged 52-57 years & 281 & 194 & 104 & 23 \\
Size of random sample & 30 & 30 & 30 & 23 \\
Number examined & $19 *$ & 24 & 11 & 14 \\
\hline
\end{tabular}

*One subject was excluded from part of the statistical analysis.

There was a high lapse rate. Measurement of oesophageal pressure cannot be done without the cooperation of the subject and no effort was made to compel attendance from those who were unwilling to come. Each person who failed to keep his first appointment was offered several more, but the reluctant attender often refused oesophageal intubation and nothing was gained by encouraging his attendance. Thus this work reports the results in those men who were sufficiently brave, frightened, interested, hopeful, grateful, ill, or well to attend and cooperate. It is impossible to say how this has influenced the results, but there is no reason to suppose that this influence will have been exerted more in one radiological category than another, and comparison of the mean results in different categories is probably justifiable.

Eight of these 68 miners had never worked on the coalface. They were employed as power station attendant, colliery wages clerk, washery foreman, weighman, winding-engine man, screener, horsekeeper, and wagon man. The horsekeeper had worked underground for 40 years, the others not at all. Seven cases of asbestosis aged 45 to 62 (mean age 54) were also examined. These were attending the out-patient department on account of respiratory symptoms and all had abnormal chest radiographs. These cases will be discussed in greater detail in another paper.

All subjects were examined seated. Maximum voluntary ventilation was determined using a mouthpiece, valve-box, and plastic bag; the mean of three attempts of 15 seconds' duration was recorded after one practice run. The volume was not corrected to body temperature, and the frequency of respiration was not systematically recorded.

Elastance and non-elastic resistance were calculated by the method of Mead and Whittenberger (1953). Intraoesophageal pressure, minus pressure in the mouth, was measured with an air-filled balloon passed through the nose, and was displayed on an oscilloscope. Velocity of air flow was measured at the mouth with a wire-mesh pneumotachograph (Lilly, 1950) and tidal air with a spirometer with a light bell (Dornhorst, Semple, and Young, 1953). These were all displayed simultaneously on an oscilloscope and the resulting records were photographed. Preliminary experiments established that the oesophageal balloon and the pneumotachograph gave similar responses to a square wave input $(90 \%$ response in $0.06 \mathrm{sec}$.). Simultaneous records from pneumotachograph and spirometer showed that the lag in the spirometer was never greater than $0.03 \mathrm{sec}$. at all respiratory frequencies from 15 to 70 cycles per minute. 


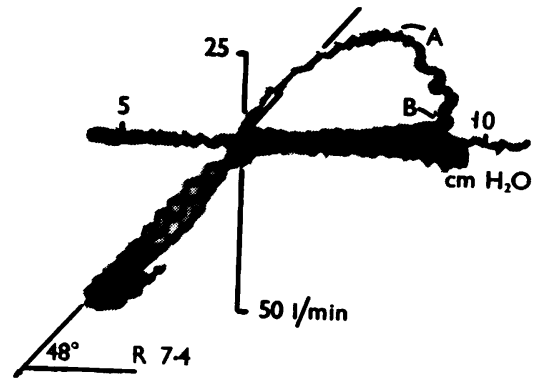

FIG. 1.-Tracing obtained by method of Mead and Whittenberger (1953). Abscissa = intraoesophageal pressure in $\mathrm{cm}$. of $\mathrm{H}_{2} \mathrm{O}$. Ordinate $=$ velocity in litres per minute. Inspiration downwards. The cotangent of the angle, $48^{\circ}$, is proportional to the resistance. In expiration the resistance is non-linear and rises to infinity at point $B$.

In many subjects the non-elastic resistance alters throughout the respiratory cycle, increasing with increasing velocity of air flow and also with diminishing chest volume (Dayman, 1951). In order to get comparable figures, the resistance has been measured during inspiration only, by fitting a straight line to the record obtained at velocities of less than $60 \mathrm{l}$./min., represented by a line some $\mathbf{2 0 - 3 0 ~ m m}$. long on the photographic record (Fig. 1).
The resistance is proportional to the slope of this line. The non-elastic resistance was worked out from three or more breaths in each subject, and the result is the mean of these.

In the older group a pressure volume diagram for the lung during normal respiration was also photographed, and the non-elastic work of respiration was calculated from the area of the closed loop in two successive breaths (standard error $\pm 9 \%$ of the mean). A time base was included on the pressure volume record, so that the ventilation rate could be determined. Elastance was also determined from the pressure volume diagram and gave good agreement with the figure obtained by the method of Mead and Whittenberger (correlation coefficient = $0 \cdot 885$ ). The standard error of replicate determinations of elastance was \pm 0.3 units.

The calibration of the instruments was checked during and after each test with standard pressures measured with a water manometer, standard volumes measured with a spirometer, and a standard flow rate supplied by a pump which delivered about one litre per second (confirmed, over the course of one minute, with a dry gas meter, at the end of each experiment). All volumes were measured at ambient temperature and pressure, and have not been corrected. During these investigations the subjects chose their own rate and depth of respiration. They were encouraged to breathe normally during the determination of elastance, resistance, and non-elastic work, but, in fact, the ventilation was usually rather large, ranging from 10.1 to $321 . / \mathrm{min}$. (mean $17.91 . / \mathrm{min}$.).

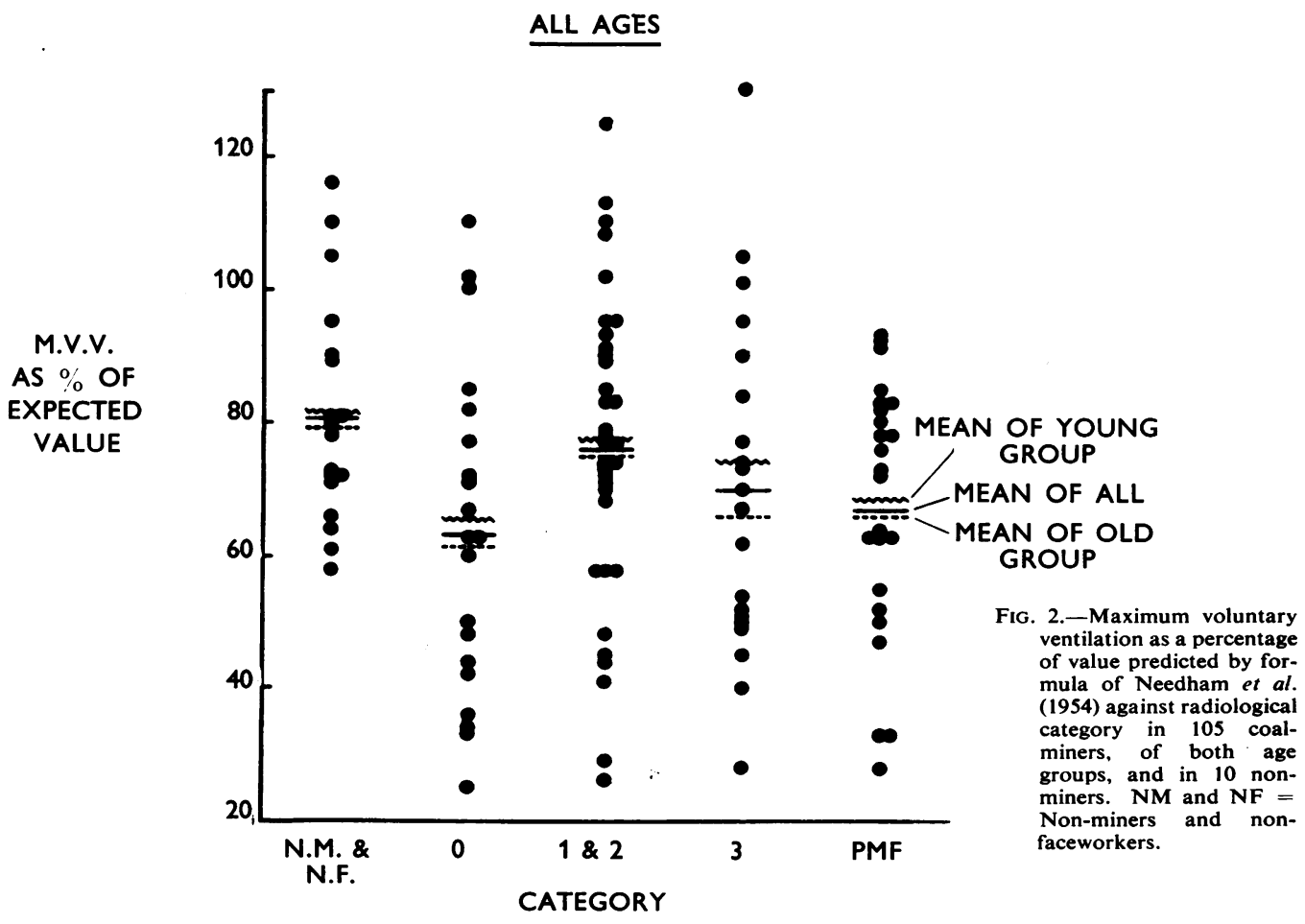


TABLE 3

RESULTS IN YOUNGER MEN

\begin{tabular}{|c|c|c|c|c|c|c|}
\hline $\begin{array}{c}\text { Radiological } \\
\text { Category }\end{array}$ & Number & $\underset{\text { (years) }}{\text { Mean Age }}$ & $\begin{array}{l}\text { Mean } \\
\text { M.V.V.F } \\
\text { (1./min.) }\end{array}$ & $\begin{array}{c}\text { Mean } \\
\text { Elastance } \\
\left(\mathrm{cm} . \mathrm{H}_{2} \mathrm{O} / 1 .\right)\end{array}$ & $\begin{array}{c}\text { Mean } \\
\text { Inspiratory } \\
\text { Resistance } \\
\text { (cm. } \mathrm{H}_{\mathbf{2}} \mathrm{O} / \mathrm{l} . / \mathrm{sec} \text { ) }\end{array}$ & $\begin{array}{c}\text { Mean } \\
\text { Dyspnoea }\end{array}$ \\
\hline 0 Non-miners & S.D. $\quad 10$ & $\begin{array}{l}34 \\
4 \cdot 7\end{array}$ & $\begin{array}{r}107 \cdot 0 \\
23 \cdot 7\end{array}$ & $\begin{array}{l}4 \cdot 5 \\
1 \cdot 3\end{array}$ & $\begin{array}{l}1 \cdot 3 \\
0 \cdot 49\end{array}$ & $\begin{array}{l}0 \cdot 2 \\
0.63\end{array}$ \\
\hline $\begin{array}{l}1 \text { Miners } \\
3 \\
\text { P.M.F. }\end{array}$ & $\begin{array}{lr}\text { S.D. } & 9 \\
\text { S.D. } & 9 \\
\text { S.D. } & 9 \\
\text { S.D. } & 10\end{array}$ & $\begin{array}{l}39 \\
5 \cdot 9 \\
38 \\
2 \cdot 8 \\
40 \\
3 \cdot 2 \\
43 \\
3 \cdot 4\end{array}$ & $\begin{array}{l}80 \cdot 1 \\
29 \cdot 3 \\
99 \cdot 1 \\
28 \cdot 3 \\
92 \cdot 1 \\
29 \cdot 9 \\
81 \cdot 4 \\
26 \cdot 9\end{array}$ & $\begin{array}{l}4 \cdot 2 \\
1 \cdot 2 \\
4 \cdot 4 \\
1 \cdot 5 \\
5 \cdot 7 \\
1 \cdot 8 \\
6 \cdot 4 \\
2 \cdot 7\end{array}$ & $\begin{array}{l}2 \cdot 4 \\
1 \cdot 64 \\
2 \cdot 1 \\
1 \cdot 26 \\
2 \cdot 0 \\
1 \cdot 11 \\
2 \cdot 3 \\
1 \cdot 21\end{array}$ & $\begin{array}{l}0.9 \\
1.17 \\
1.2 \\
1.09 \\
1.4 \\
1.51 \\
1.8 \\
1.32\end{array}$ \\
\hline \multicolumn{3}{|c|}{$\begin{array}{l}\text { Significance } \\
\text { All miners compared with non-miners }\end{array}$} & $\begin{array}{c}\text { Not significant } \\
\text { t test } \\
(45 \mathrm{~d} \text {.f.) } \\
2.00\end{array}$ & $\begin{array}{c}\text { Not significant } \\
\text { t test } \\
\text { (45 d.f.) } \\
1.09\end{array}$ & $\begin{array}{c}t \text { test } \\
(44 \text { d.f. }) \\
2.21 \\
P<0.05\end{array}$ & $\begin{array}{c}x^{2}=5.85^{*} \\
(1 \text { d.f. }) \\
P<0.02\end{array}$ \\
\hline
\end{tabular}

*Based on number of men without dyspnoea.

TABLE 4

RESULTS IN OLDER MEN

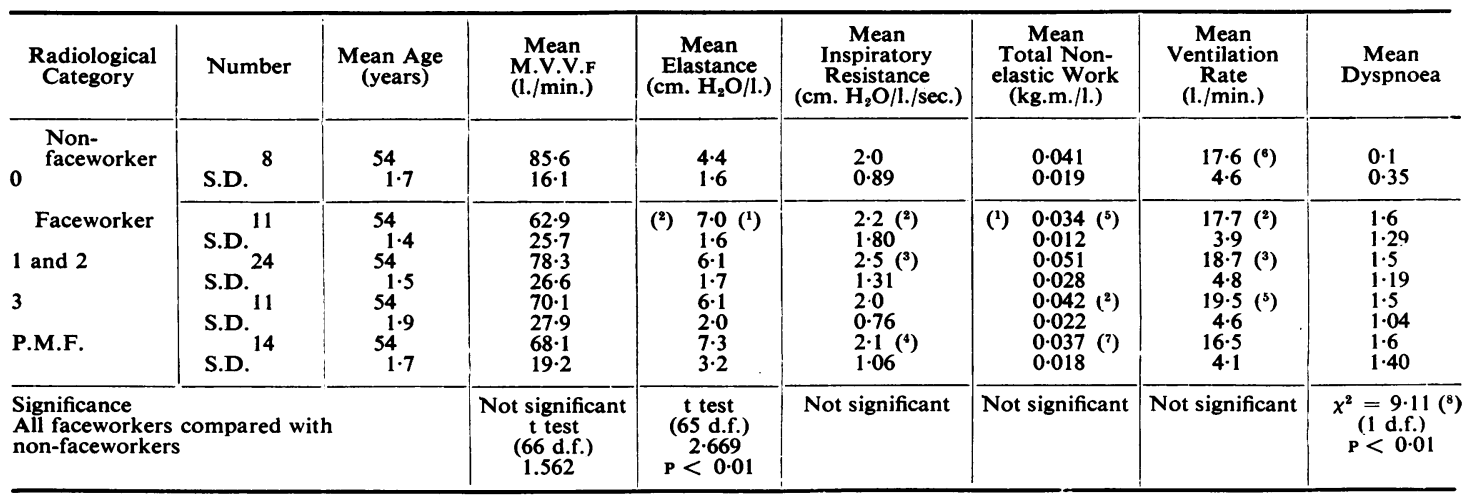
(1) Excluding subject No. 265
(2) 10 subjects only
(3) 23 subjects only
(5) 9 subjects only
(6) 7 subjects only
(7) 11 subjects only
(4) 12 subjects only
(8) Based on number of men without dyspnoea

The radiograph taken on the day of examination was classified by three observers independently and the final category was decided from these three opinions as described by McCallum and Browne (1955). The radiological categories used are those described by Fletcher, Mann, Davies, Cochrane, Gilson, and HughJones (1949).

Dyspnoea was assessed from the subject's account of his symptoms, and classified numerically (Fletcher, 1952).

\section{Results}

The results for the younger group are summarized in Table 3 and for the older group in Table 4 (Figs. 2 to 7). Statistical tests are summarized in Table 5.

Maximum Voluntary Ventilation.-Fig. 2 depicts the results of the test of maximum voluntary ventilation (M.V.V.) in all 105 miners and 10 controls, and the means in the different categories. In order to allow for the different ages and sizes of the subjects the results have been expressed as a percentage of the value predicted by the formula of Needham, Rogan, and McDonald (1954) who used the same method. In Tables 3 and 4 the results are expressed in litres per minute at ambient temperature and pressure. In miners the M.V.V. is lower than in non-miners, but this difference is not significant at the $5 \%$ level. Simple pneumoconiosis appears to have no effect on the M.V.V. In the subjects with simple pneumoconiosis the M.V.V. is not significantly lower than in the non-miners or non-faceworkers, and is actually higher than in faceworkers without pneumoconiosis. In all those with P.M.F., and in the young faceworkers without pneumoconiosis, however, the M.V.V. is significantly 
FIG. 3.-Elastance in the young group.

Elastance in cm. of $\mathrm{H}_{2} \mathrm{O} / 1$ vertically, radiological category horizontally.

The horizontal line represents the mean elastance of each category.

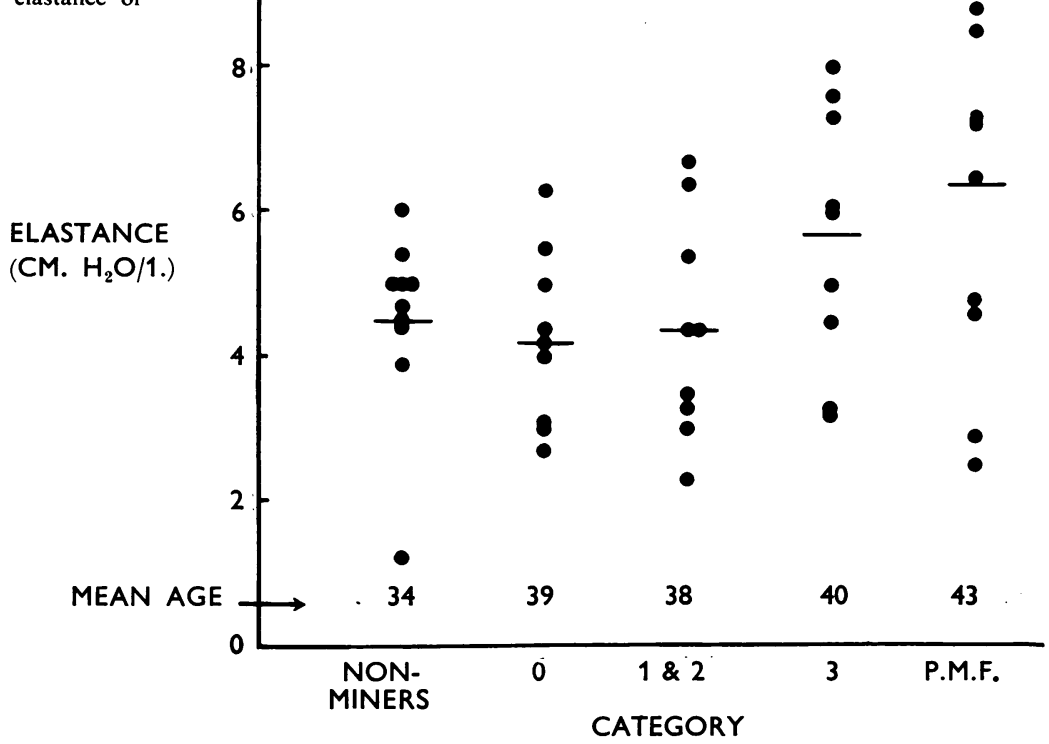

reduced (Table 5). There is a trend of decreasing M.V.V. with increasing radiological abnormality. This is shown by both the old and the young group, but in neither case does the trend reach statistical significance $(P<0 \cdot 2)$.

It will be seen in Fig. 2 that the mean M.V.V. of miners and non-miners alike has fallen below normal when expressed as a percentage of the predicted value. This is probably due to the fact that the prediction formula is based on the best of two or three attempts, while the result reported here is the mean of three.

Elastance.-The elastance reported here is the "functional" (dynamic) elastance which obtains during normal respiration, rather than the "static elastance". Figs. 3 and 4 depict the individual findings in the subjects arranged according to their radiological classification, together with the means of the different radiological groups. The means and standard deviations are also given in Tables 3 and 4 and can be compared with the mean elastance of normal individuals of $4.66 \mathrm{~cm} . \mathrm{H}_{2} \mathrm{O} / 1$. (mean of 303 observations reported in the literature by Bondurant, Hickam, and Isley, 1957; Butler and Smith, 1957; Butler, White, and Arnott, 1957; Cherniack, 1956; Frank, Mead, Siebens, and Storey, 1956; Marshall and Dubois, 1956a; McIlroy, Marshall, and Christie, 1954; Otis, Fenn, and Rahn, 1950). The published figures were not all obtained

TABLE 5

TESTS OF SIGNIFICANCE ( $t$ TEST)

\begin{tabular}{|c|c|c|c|c|c|c|}
\hline Group & Test & Category & Compared with & $\begin{array}{l}\text { Degrees of } \\
\text { Freedom }\end{array}$ & $\mathbf{t}$ & $\mathbf{P}$ \\
\hline Young men & $\begin{array}{l}\text { M.V.V.F } \\
\text { Elastance }\end{array}$ & $\begin{array}{l}0 \\
\text { P.M.F. } \\
0 \\
\text { P.M.F. } \\
\begin{array}{l}\mathbf{M} \\
2\end{array}\end{array}$ & $\begin{array}{l}\text { Non-miners } \\
\text { Non-miners } \\
\text { Non-miners } \\
\text { Non-miners } \\
\text { Non-miners }\end{array}$ & $\begin{array}{l}17 \\
17 \\
17 \\
17 \\
26\end{array}$ & $\begin{array}{l}2 \cdot 214 \\
2 \cdot 262 \\
0 \cdot 468 \\
2 \cdot 002 \\
0 \cdot 804\end{array}$ & $\begin{array}{l}<0.05 \\
<0.05 \\
\text { Not significant } \\
\text { Not significant } \\
\text { Not significant }\end{array}$ \\
\hline Old men & $\begin{array}{l}\text { M.V.V.F } \\
\text { Elastance } \\
\text { Total non elastic work }\end{array}$ & $\begin{array}{l}\text { P. } \\
\text { P.M.F. } \\
0 \\
\text { P.M.F. } \\
\begin{array}{l}1 \\
\mathbf{2}\end{array} \\
\quad \mathbf{0} \\
\text { P.M.F. }\end{array}$ & $\begin{array}{l}\text { Non-faceworkers } \\
\text { Non-faceworkers } \\
\text { Non-faceworkers } \\
\text { Non-faceworkers } \\
\text { Non-faceworkers } \\
\text { Non-faceworkers } \\
\text { Non-faceworkers }\end{array}$ & $\begin{array}{l}17 \\
20 \\
16 \\
20 \\
41 \\
15 \\
20\end{array}$ & $\begin{array}{l}1 \cdot 886 \\
2 \cdot 171 \\
3 \cdot 478 \\
2 \cdot 436 \\
2 \cdot 479 \\
0 \cdot 922 \\
0 \cdot 439\end{array}$ & $\begin{array}{l}\text { Not significant } \\
<0.05 \\
<0.01 \\
<0.05 \\
<0.02 \\
\text { Not significant } \\
\text { Not significant }\end{array}$ \\
\hline
\end{tabular}


by the method used in this paper, nor were they all in subjects of the same age ranges, but the different methods give results which fall within the range 2.7 to 11.1 and no definite association with age in adults has been established (Marshall, 1957; Butler et al., 1957).

Amongst the younger men work underground is not associated with any significant alteration of pulmonary elastance. There is no convincing evidence that either simple pneumoconiosis or P.M.F. is accompanied by any such alteration. The apparent trend of increasing elastance with increasing radiological abnormality (Fig. 3) is suggestive but not statistically significant. Similarly the result in P.M.F. is not significantly higher than in the non-miners.

Amongst the older men the elastance is significantly higher in faceworkers than in non-

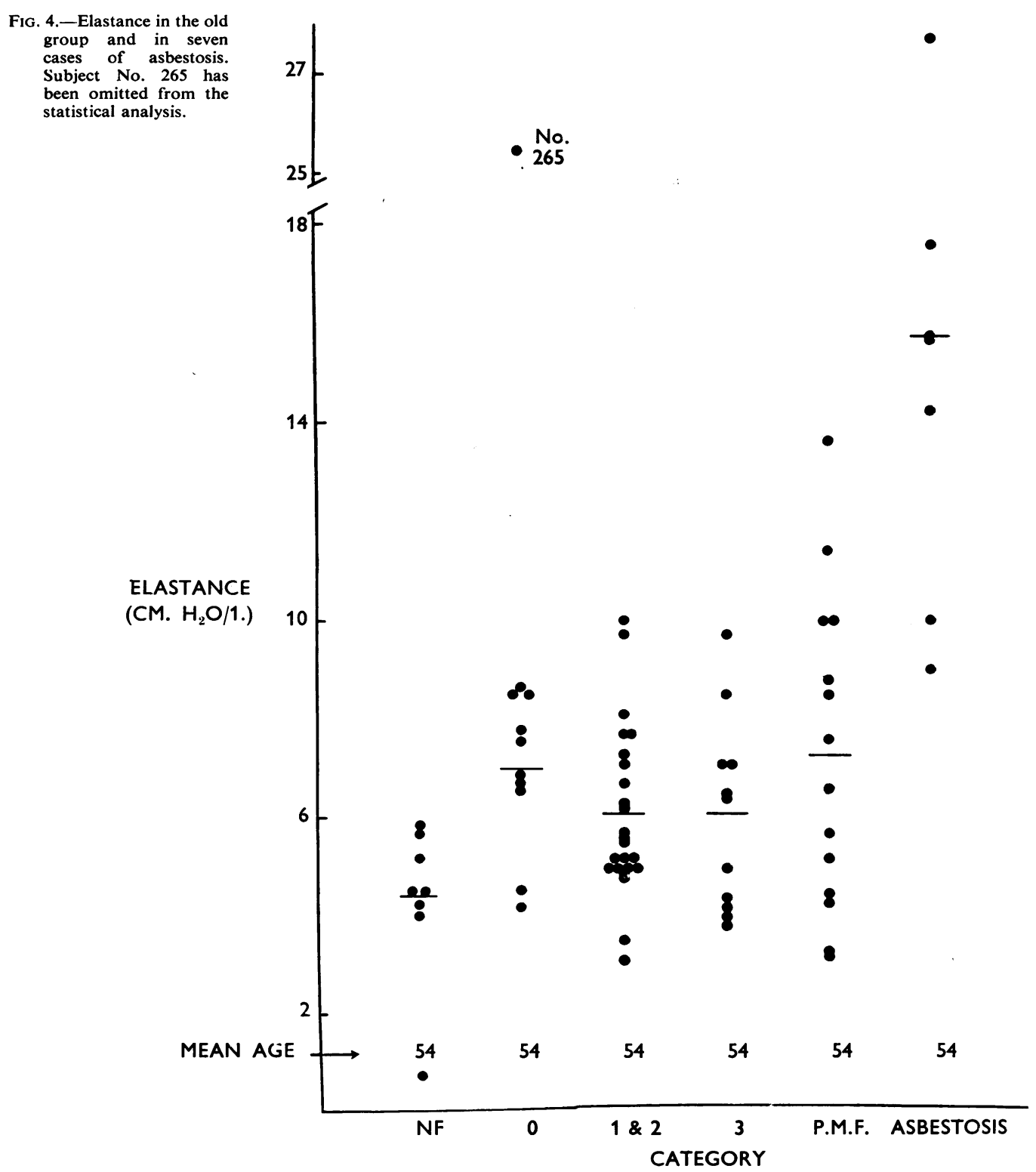


FIG. 5.-Inspiratory resistance in the young group.

The horizontal line represents the mean resistance of each category.

Fig. 6.-Inspiratory resistance in the old group.

FiG. 5
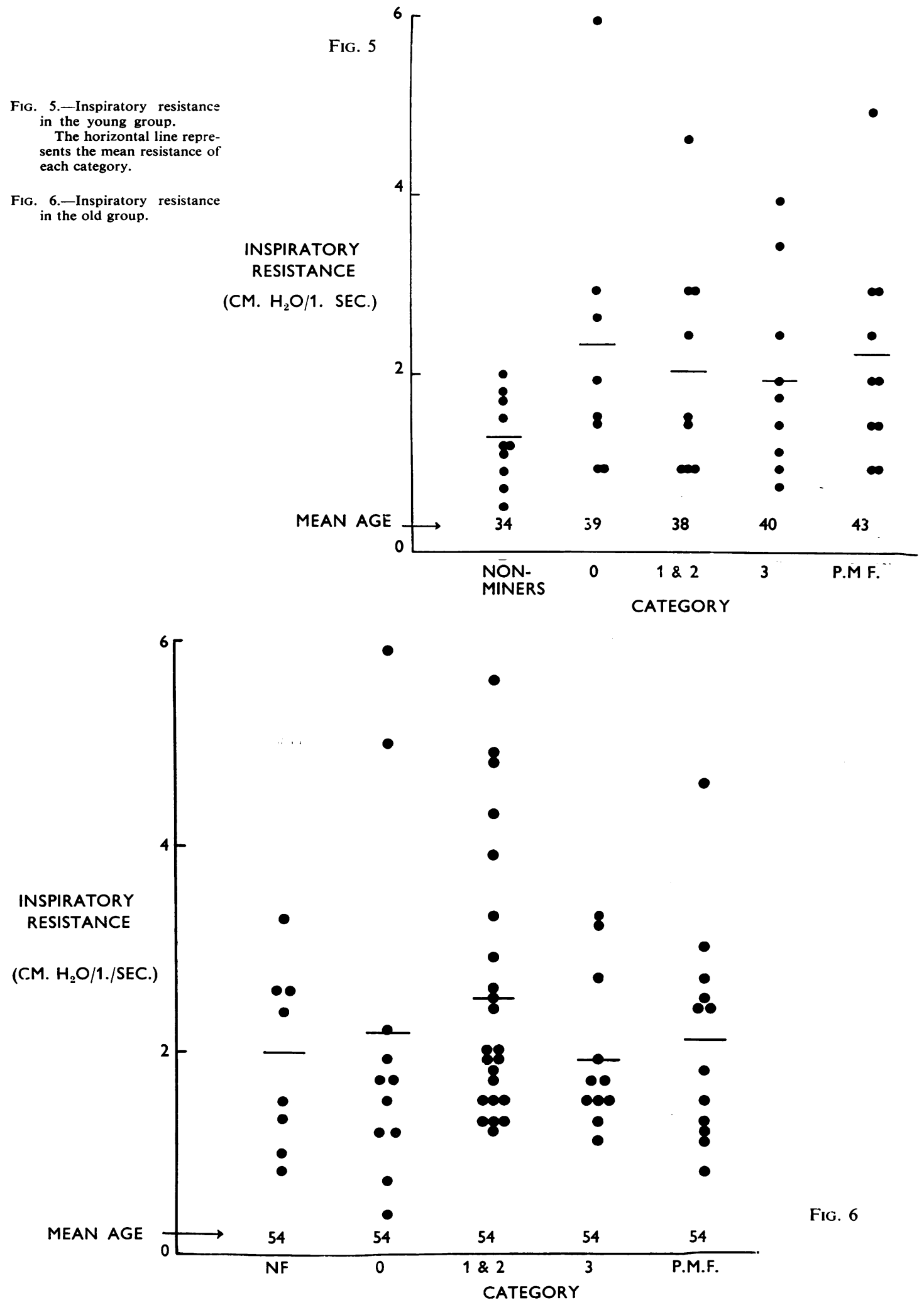

FIG. 6 
FIG. 7.-Non-elastic work of respiration during quiet breathing in the old group. The horizontal line represents the mean work of each category.

The mean ventilation rate in each category is given at the bottom of the figure.

Subject No. 265 has been omitted from the statistical analysis.

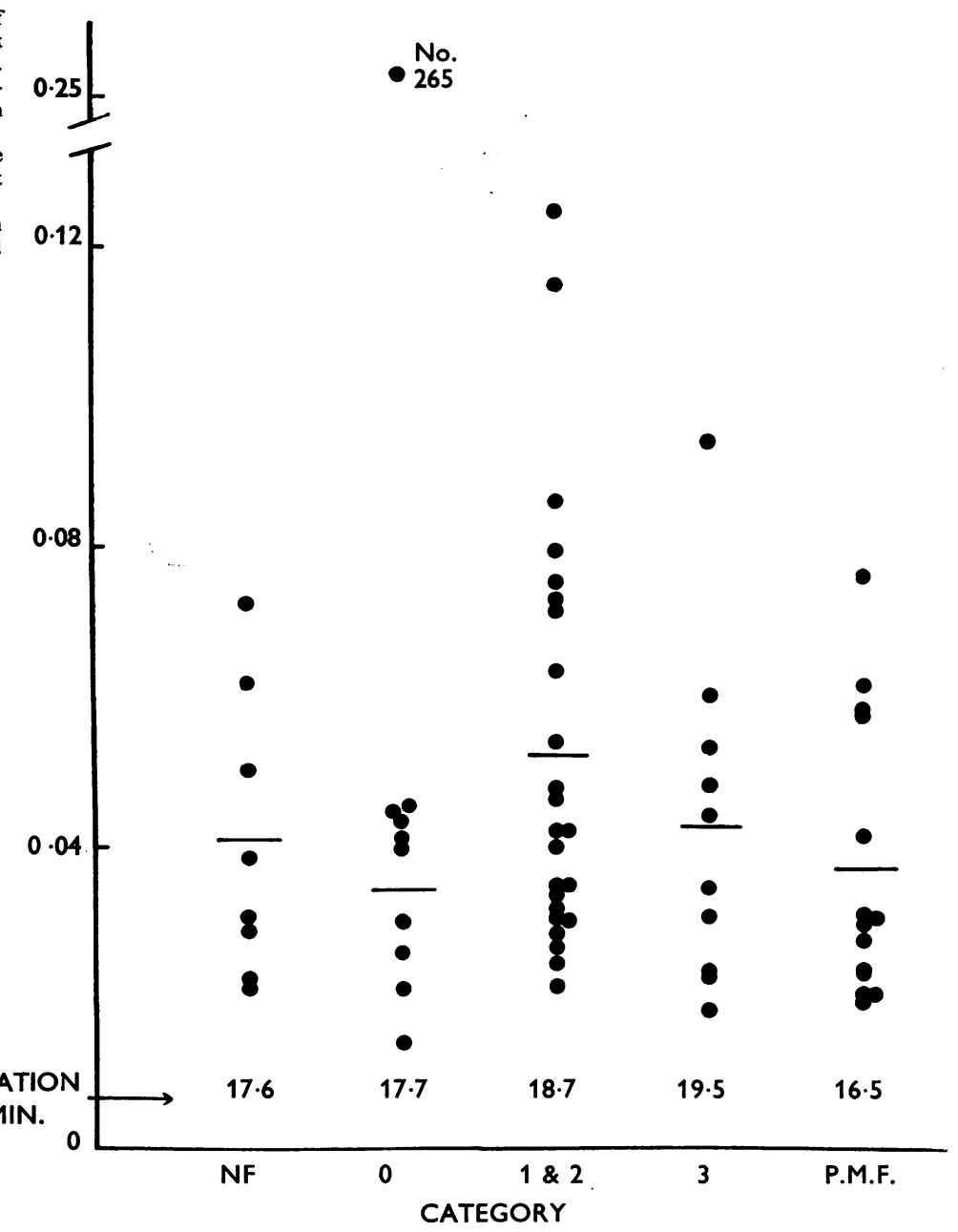

faceworkers. It is significantly increased in simple pneumoconiosis, but it is increased even more in faceworkers without pneumoconiosis. In older men with P.M.F. the elastance is also significantly increased but it is no higher than in faceworkers without pneumoconiosis. If the older men are compared with the younger, elastance is found to be significantly higher among the older faceworkers without pneumoconiosis, and in categories 1 and 2 . The difference between young and old is not significant in category 3 or in P.M.F. Amongst those men who have never worked at the face the elastance is the same in young and old.

Non-elastic Resistance.-Figs. 5 and 6 show the results for non-elastic resistance during inspiration, and the means and standard deviations are given in Tables 3 and 4 . The mean can be compared with the mean resistance for normal subjects of $1.96 \mathrm{~cm}$. $\mathrm{H}_{2} \mathrm{O} / \mathrm{l}$./sec. (Mean of 69 determinations in normal subjects by this method: Marshall, 1957; Marshall and Dubois, 1956a; Mead, Lindgren, and Gaensler, 1955; Mead and Whittenberger, 1953.) One of these papers shows that there is a tendency for resistance to rise with age, but the highest resistance was only $2.9 \mathrm{~cm} . \mathrm{H}_{2} \mathrm{O} / \mathrm{l} . / \mathrm{sec}$. (Mead et al., 1955). It can be seen that the young controls gave a significantly lower result than all the other subjects. The reason for this is unknown. All other subjects gave very similar results regardless of radiological abnormality.

Total Non-elastic Work.-The work of breathing was estimated only in the older subjects. In Fig. 7 and Table 4 non-elastic work is expressed in kilogram-metres per litre. Theoretically this is 
directly proportional to resistance, if the flow pattern is constant. In fact the correlation coefficient between non-elastic work of inspiration (during which resistance remains relatively constant) and inspiratory resistance was $+0.65(\mathrm{P}<0.001)$. Though work done per litre of air flow probably increases with increasing ventilation in each individual, it is a better basis for the comparison of individuals with different ventilation rates than the work done per minute, which has a much greater dependence on the minute-volume. Moreover it is difficult to predict the minute-volume from the record obtained during a single respiratory cycle, especially when there may be a pause between successive cycles. The ventilation rates recorded in this paper have been calculated without allowing for any pause, and consequently the figures are rather high. However, the mean ventilation rates in the different categories were similar, and the scatter about the mean was not great.

The individual and mean results shown in Fig. 7 may be compared with the mean for normal individuals of about $0.035 \mathrm{~kg} . \mathrm{m}$./l. This figure is seldom exceeded in subjects without dyspnoea. Unfortunately, very little information about non-elastic work of breathing has been published. Calculation from the formula of Otis et al. (1950), assuming ventilation at 20 breaths per minute, at 20 litres per minute, and a resistance of $1.96 \mathrm{~cm} . \mathrm{H}_{2} \mathrm{O} / \mathrm{l}$./ $\mathrm{sec}$., gives a figure of $0.029 \mathrm{~kg} . \mathrm{m} . / \mathrm{l}$. Butler (1957) quotes $0.0103 \mathrm{~kg} . \mathrm{m}$./l. in five normal subjects and calculations from the findings of Mcllroy et al. (1954) give $0.029 \mathrm{~kg} . \mathrm{m} . / \mathrm{l}$. Cherniack (1956) found $0.0258 \mathrm{~kg} . \mathrm{m} . / 1$. in seven normal subjects. It seems probable, therefore, that the means in all older coalminers are slightly higher than normal. There is a trend of decreasing work with increasing radiological abnormality but this trend does not reach significance at the 5\% level. Amongst those men without pneumoconiosis the non-elastic work was lower in the faceworkers than in those who had never worked at the coal-face, but this difference was not statistically significant.

Dyspnoea.-In Tables 3 and 4 is given the mean degree of subjective dyspnoea assessed by the numerical scale running from 0 to 5 described by Fletcher (1952). It will be seen that there was significantly less dyspnoea among the non-miners and those colliery employees who had never worked underground. There was no excess of dyspnoea in miners without pneumoconiosis. Amongst the older miners there was no association between dyspnoea and the radiological category of pneumoconiosis, but in the younger men there was a trend towards increasing dyspnoea with increasing radio- logical abnormality. This may have been a function of their increasing age. So few subjects complained of the severer grades of dyspnoea that further analysis of this symptom is not justified.

\section{Discussion}

In a study of this type the method of selection of the subjects is of fundamental importance (Carpenter et al., 1956) and it must be admitted that in this study selection has not been ideal. The use of hospital patients adds to the difficulties of interpretation of the results. Though some attended simply for a routine radiograph of the chest, others had symptoms of chest disease. This group might therefore be expected to give abnormal results in the various tests. This does not, however, necessarily invalidate the comparison of the results in one radiological category with those in another, as there is reason to suppose that those with respiratory symptoms were equally distributed throughout the various categories (Newell and Browne, 1955). However, there was considerable difference in the mean age of the patients in the different radiological categories and this may influence the results. It would therefore be unwise to attach too much importance to the results obtained in these hospital patients, and they have been included only because they show a pattern similar to that obtained in the group of older men and thus lend some support to the conclusions drawn from this group.

The men in the older group were all about the same age and were selected randomly, but there was a high lapse rate and this could have affected the results. Moreover bias in the results could have been caused by selection of the men who originally attended for chest radiographs, the men from whom the random sample was taken. This point is discussed by McCallum and Browne (1955) who conclude that the sample of about $90 \%$ of the mining population is a representative one. It is possible that the more severely disabled men might have retired from mining before the radiological survey was carried out and this might have influenced in particular the composition of the group with progressive massive fibrosis, in whom symptoms were more severe. These men would have been 45-50 years of age at the time of the survey, which is early for complete incapacity, and it is believed that there cannot have been many men who had left mining for this reason. The sample which was investigated included four men who had left mining since the radiological survey.

The value of this work would have been greatly enhanced if it had been possible to investigate a reasonably large group of control subjects, in the age range 52-57. It had been hoped to collect 
TABLE 6

COMPARISON OF M.V.V. IN ELDERLY MINERS AND NON-MINERS OBTAINED BY DIFFERENT AUTHORS

\begin{tabular}{|c|c|c|c|c|c|c|c|c|c|}
\hline \multirow{3}{*}{ Author } & \multirow{3}{*}{ Sample } & \multirow{3}{*}{ Method } & \multirow{3}{*}{$\begin{array}{l}\text { Non- } \\
\text { miners }\end{array}$} & \multicolumn{6}{|c|}{ Radiological Category } \\
\hline & & & & \multirow{2}{*}{0} & \multirow{2}{*}{1} & \multirow{2}{*}{2} & \multirow{2}{*}{3} & \multicolumn{2}{|c|}{ P.M.F. } \\
\hline & & & & & & & & B & D \\
\hline $\begin{array}{l}\text { Gilson et al. (1955) } \\
\text { Mean age }\end{array}$ & $\begin{array}{c}\text { Selected miners and } \\
\text { non-miners }\end{array}$ & $\begin{array}{l}\text { Spirometer } \\
\text { M.V.V.F }\end{array}$ & $\begin{array}{l}118(10) \\
54 \cdot 3\end{array}$ & $\begin{array}{l}94(8) \\
54 \cdot 0\end{array}$ & \multicolumn{2}{|c|}{$\begin{array}{c}100(8) \\
54 \cdot 2\end{array}$} & $\begin{array}{l}81(8) \\
54.9\end{array}$ & $\begin{array}{l}61(8) \\
55 \cdot 1\end{array}$ & $\begin{array}{l}33(8) \\
55 \cdot 0\end{array}$ \\
\hline $\begin{array}{l}\text { Carpenter et al. (1956) } \\
\text { Mean age }\end{array}$ & $\begin{array}{l}\text { Three random popu- } \\
\text { lation samples combined }\end{array}$ & $\begin{array}{l}\text { F.E.V. } 0 \cdot 75 \\
\text { Indirect M.B.C. }\end{array}$ & $\begin{array}{l}88(134) \\
59 \cdot 5\end{array}$ & $\begin{array}{l}73 \cdot 8(167) \\
59 \cdot 5\end{array}$ & $\begin{array}{l}90 \cdot 3(12) \\
58 \cdot 7\end{array}$ & $\begin{array}{l}78 \cdot 4(17) \\
58 \cdot 9\end{array}$ & $\begin{array}{l}76 \cdot 8(55) \\
59 \cdot 8\end{array}$ & - & - \\
\hline $\begin{array}{l}\text { Higgins et al. (1956) } \\
\text { Mean age }\end{array}$ & $\begin{array}{l}\text { Random population } \\
\text { sample Leigh }\end{array}$ & $\begin{array}{l}\text { F.E.V. } 0.75 \\
\text { Indirect M.B.C. }\end{array}$ & $\begin{array}{l}85 \cdot 0(84) \\
59 \cdot 4\end{array}$ & $\begin{array}{l}76 \cdot 0(101) \\
59 \cdot 1\end{array}$ & $\begin{array}{l}91 \cdot 5(6) \\
57 \cdot 3\end{array}$ & $\begin{array}{l}86 \cdot 0(7) \\
59 \cdot 0\end{array}$ & $\begin{array}{l}79 \cdot 8(8) \\
58 \cdot 8\end{array}$ & $73 \cdot 6$ & $6(10)$ \\
\hline
\end{tabular}

* Experimental results have been multiplied by $1 \cdot 1$ to make them comparable with the results of other workers.

In this table figures in parenthesis refer to the number of men who contributed to the mean figure which is quoted.

subjects from another industry in this area but the number of men who were prepared to undergo tests was too small to make this worthwhile. It has therefore been necessary to rely on normal values reported in the literature.

Maximum Voluntary Ventilation.-The results of this investigation confirm and extend those of Carpenter et al. (1956), who also found a surprisingly low mean M.V.V. in elderly miners without pneumoconiosis, although they used a different method. Their results were expressed at B.T.P.S. by multiplying by 40 the mean volume of air expelled in three-quarters of a second during three or four forced expirations (the time being measured after the expulsion of the first $100 \mathrm{ml}$.). This correlates well with M.V.V. recorded with a spirometer (Kennedy, 1953). The M.V.V.s reported in this paper are expressed at ambient pressure and temperature, and consequently are all rather lower than those reported by Carpenter et al. In Table 6 the results in the older group reported here have been multiplied by $1 \cdot 1$ to bring them approximately to B.T.P.S. and are compared with the findings of several other authors. The group most closely resembling the men in this investigation are the working miners in Colliery $\mathbf{L}$. The subjects of the present investigation gave results very similar to these men and to the other random samples, the chief difference being the lower figure in Category 1 and the higher figure in Category 2. Gilson and Hugh-Jones (1955) report much higher figures in non-miners and in simple pneumoconiosis, but lower ones in P.M.F. The high figures are probably due to the method used, as they recorded the volume with a spirometer, which, they demonstrated, tends to over-estimate in the intermediate ranges. The low figures in P.M.F. are probably the result of their investigating subjects with more advanced disease. In the present work the majority of subjects had either Category A or B of P.M.F. (Table 7), but if only cases of P.M.F. Category B are considered the mean M.V.V. is still as high as 73.2 (about 80 at B.T.P.S.) 1./min. Amongst the men with P.M.F. investigated by Higgins, Oldham, Cochrane, and Gilson (1956) nine out of the 10 were in category A or B (Higgins, 1958) and their results were very similar to the present investigation.

All authors agree that the M.V.V. is lowered in P.M.F. They also agree (Table 6) that elderly miners without pneumoconiosis have a lower M.V.V. than those with simple pneumoconiosis, categories 1 and 2 , and lower than non-miners. The possible reasons for this are discussed by Carpenter et al. (1956) who

TABLE 7

RADIOLOGICAL CATEGORY OF P.M.F.

\begin{tabular}{|c|c|c|c|}
\hline \multicolumn{2}{|c|}{ Younger Men } & \multicolumn{2}{|c|}{ Older Men } \\
\hline Case No. & Radiograph & Case No. & Radiograph \\
\hline $\begin{array}{l}138 \\
142 \\
144 \\
162 \\
165 \\
167 \\
173 \\
175 \\
177 \\
178\end{array}$ & $\begin{array}{ll}3 & \mathrm{C} 6 / 6 \\
3 & \mathrm{~A} 4 / 2 \\
3 & \mathrm{~B} 2 / 4 \\
3 & \mathrm{~A} 3 / 3 \\
3 & \mathrm{~A} 5 / 1 \\
3 & \mathrm{~B} 3 / 0 \\
3 & \mathrm{~A} 3 / 4 \\
3 & \mathrm{C} 4 / 4 \\
3 & \mathrm{~B} 3 / 3 \\
3 & \mathrm{~B} 4 / 4\end{array}$ & $\begin{array}{l}209 \\
210 \\
245 \\
250 \\
253 \\
254 \\
256 \\
257 \\
264 \\
282 \\
285 \\
299 \\
300 \\
306\end{array}$ & $\begin{array}{ll}3 & \mathrm{~B} 2 / 1 \\
2 & \mathrm{~B} 2 / 0 \\
2 & \mathrm{~A} 2 / 1 \\
3 & \mathrm{~A} 3 / 4 \\
2 & \mathrm{~B} 4 / 1 \\
3 & \mathrm{~B} 5 / 4 \\
3 & \mathrm{~A} 1 / 1 \\
3 & \mathrm{~B} 4 / 1 \\
3 & \mathrm{~A} 4 / 4 \\
2 & \mathrm{~A} 0 / 1 \\
3 & \mathrm{~B} 5 / 5 \\
2 & \mathrm{~A} 4 / 2 \\
3 & \mathrm{~B} 4 / 3 \\
3 & \mathrm{D} 4 / 2\end{array}$ \\
\hline
\end{tabular}


conclude that generalized emphysema may account for it. The present investigation has not provided statistically significant confirmation of their demonstration that simple pneumoconiosis also lowers the M.V.V.

Pulmonary Elastance.-There is wide scatter of the results obtained in each radiological category. It is believed that this is not due to deficiencies of the method, but represents true differences between individuals, because there was good agreement between the elastance of 65 subjects measured by two different methods, and because the method does demonstrate considerable abnormality in asbestosis (Fig. 4). Moreover in the non-miners and non-faceworkers the mean elastance is close to the figure previously reported in normal men.

In the younger group the mean age increases with increasing severity of radiological abnormality and this throws some doubt on the relationship between radiological category and elastance observed, but no association with age could be demonstrated within each category, or in the whole of the younger group. Also Frank et al. (1956) reported no association with age over a similar age range, in normal individuals. There is no evidence that differences in body build are responsible for differences in elastance in these men, since correlation between height and elastance, within each radiological category, was demonstrable only in the young men in category 3. Such a correlation was found to occur in normal men (Marshall, 1957).

Since the elastance of those older men who have never worked at the coalface is the same as that of the young men who have never worked in a coalmine, the higher elastance of the older faceworkers must be mainly due to their having worked underground for longer than the young men. This is substantiated by the observation that in Category $O$, where the difference between young and old is most marked, the old men had, on the average, worked underground for 14 years longer than the young men, though the time spent on the coalface was only two years more.

The finding of a raised elastance in elderly faceworkers without pneumoconiosis also suggests that this change is brought about by work underground rather than by radiological pneumoconiosis.

These men, together with those who have P.M.F., form the groups in which M.V.V. is abnormally low, and elastance is abnormally high. In individual cases, however, there is no correlation between M.V.V. and elastance, which makes it difficult to accept the rather high elastance as a cause for the reduction of M.V.V.

It should be stressed that in only two out of the
97* miners did the elastance exceed the upper limit of normal, which Frank et al. (1956) put at $11 \cdot 1 \mathrm{~cm}$. $\mathrm{H}_{2} \mathrm{O} / \mathrm{l}$. Alterations of elastance of this order have been recorded in hypertrophic emphysema (Attinger, Goldstein, and Segal, 1956; Cherniack, 1956; Mead et al., 1955; Stead, Fry, and Ebert, 1952), and this may account for the changes demonstrated in these coal-miners. The changes in elastance in coal-miners are not, therefore, a cause of disability but are a pointer towards the nature of the lesion responsible for it.

The finding of a virtually normal elastance in the presence of massive fibrosis of the lung was unexpected. In this type of pneumoconiosis the fibrosis is not generalized but localized to welldefined areas, which, in these subjects, were never very extensive. Presumably these areas do not expand during a normal inspiration and consequently make no direct contribution to the elastance, while the elastance of the remaining lung, which does expand during inspiration, is, at any rate during quiet breathing at rest, apparently close to normal. This does not exclude the possibility that there may be an increase of elastance during deep inspiration and at larger lung volumes.

Non-elastic Resistance.-The mean non-elastic resistance is normal in these coal-miners. Marshall and Dubois (1956b) report a moderate increase of non-elastic resistance in their single case of anthracosis (aged 57) but this falls well within the range depicted in Fig. 6.

The inspiratory resistance does not correlate with the maximum voluntary ventilation nor with the maximum flow-rate during forced inspiration or expiration. Resistance is not necessarily constant throughout inspiration (Dayman, 1951) but the records have been analysed in such a way as to minimize this defect. Mead and Whittenberger (1953) reported that the pressure flow curve delineated by their method was parabolic, but in this work it was found to be more nearly linear. (The resistance reported here corresponds to $K_{1}$ of Mead and Whittenberger.) If the records were really parabolic, treating them as linear between flow rates of 0 and 60 $1 . / \mathrm{min}$. would tend to give too high a value to the resistance. Since the values obtained are no higher than those previously reported for normal individuals (and in the controls they are actually lower) this method of interpretation cannot have caused a very serious error. As total non-elastic resistance is normal during quiet inspiration it must be assumed that neither airway resistance nor tissue resistance

\footnotetext{
*Subject 306, elastance 13.6; subject 25A, elastance 11.4 (see Table 6).
} 
can have altered much. It has previously been shown that tissue resistance was not altered in a case of anthracosis (Marshall and Dubois, 1956b).

It appears that the radiological abnormality of pneumoconiosis is not associated with any narrowing or distortion of the airways demonstrable during quiet inspiration. Nor does this occur in miners without pneumoconiosis. This does not exclude the possibility that such distortion may occur during expiration, or may be manifest at faster flow rates during inspiration. Account is taken of these possibilities in the measurement of non-elastic work of respiration. For example, in subject 265 inspiratory resistance was $5.9 \mathrm{~cm} . \mathrm{H}_{2} \mathrm{O} / \mathrm{l}$./sec. at slow flow rates but rose to 21.8 during fast inspiration and to $40.7 \mathrm{~cm} . \mathrm{H}_{2} \mathrm{O} / \mathrm{l} . / \mathrm{sec}$. during fast expiration. Total non-elastic work was very high, $0.253 \mathrm{~kg} . \mathrm{m} . / \mathrm{l}$., at a ventilation rate of 14 litres per minute.

Non-elastic Work of Respiration.-The nonelastic work of breathing is a measure of integrated airways resistance. It was highest in Category 1 and 2 , being $0.040 \mathrm{~kg} . \mathrm{m} . / \mathrm{l}$. in Category 1 and 0.055 kg.m./l. in Category 2. It was lower in Category 3 and nearly normal in P.M.F. The pattern presented by the means of the individual results in the various categories was remarkably similar to the pattern of mean M.V.V. in the same men (Figs. 2 and 7), low M.V.V. occurring with low non-elastic work. It had been supposed that a low M.V.V. would be accompanied by high non-elastic work, and this unexpected finding requires further consideration.

Non-elastic work was measured during relatively quiet respiration and might not necessarily correlate very well with reduction of a maximum ventilatory effort. However, correlation of the two has been reported by Cherniack (1956) in cases of emphysema and in the present investigation a significant, but small, negative correlation between non-elastic work and M.V.V. was established $(r=-0.312)$. Nevertheless the mean non-elastic work in different radiological categories shows a positive correlation with M.V.V. This could be entirely fortuitous but could be explained in one of the following ways. First, there are theoretical reasons for supposing that a high pulmonary elastance helps to maintain patency of the airways, and high elastance was demonstrated in the two groups who give low figures for non-elastic work. There was not, however, any correlation between elastance and non-elastic work, either in these two groups or in the series of miners as a whole, so that this would appear not to be the explanation. Secondly, non-elastic work done on the lung is not equal to the total non-elastic work done by the subject. A variable proportion of the total is required to move the chest wall and dia- phragm. If the proportion of the available power which goes to move the thoracic walls is increased in certain individuals, then in these one might expect to see a reduction in the work done on the lung during normal ventilation accompanied by a reduction in maximum ventilatory ability. In these individuals the M.V.V. would be limited by excessive frictional resistance in the chest wall rather than by resistance in the airways; such is the picture presented by the faceworkers without pneumoconiosis, and by miners with P.M.F.

A rather similar observation has been made by Gandevia and Prime (1957) who found that the maximum intrathoracic pressure during a forced expiration in 10 patients with asthma or chronic bronchitis was reduced by inhalation of isoprenaline. They suggest that this may be due to limitation of the speed with which the chest wall can move. Similarly McKerrow, McDermott, Gilson, and Schilling (1958), measuring the airways resistance in cotton workers during expiration at high flow rates, found that alterations in the indirect M.B.C. and airways resistance are not very highly correlated, suggesting that airways resistance is not the sole factor limiting a maximum expiratory effort. A limitation of the speed of movement of the chest wall would not be recognized by measuring the maximum static pressure which can be sustained by the expiratory muscles. This has been shown (Carpenter et al., 1956) to be unrelated to the M.V.V. in miners.

It is suggested, therefore, that in some miners the M.V.V. is limited by frictional resistance in the chest wall, rather than in the lungs, and that this occurs particularly frequently in faceworkers without pneumoconiosis, and in those with P.M.F. It appears to be responsible for the low mean M.V.V. obtained in these men.

In the majority of miners, however, airways resistance is the limiting factor and this accounts for the negative correlation between non-elastic work and M.V.V. recorded in these subjects and between airways resistance and M.V.V. recorded by McDermott (quoted by Carpenter et al., 1956).

If non-elastic work, expressed in kilogram-metres per litre, is taken as a measure of the mean nonelastic resistance, as has been suggested in this paper, then in those miners without pneumoconiosis the non-elastic resistance appears to be highest in those men who have never worked at the coalface. This is misleading, and the probable reason why non-elastic work is lower in the faceworkers is because of an alteration in the flow pattern of respiration such that a steady low rate of flow throughout inspiration and expiration replaces the normal pattern of periods of high flow alternating with periods of negligible flow. This alteration could be imposed by frictional 
resistance in the chest wall. Unfortunately no records of flow patterns were taken in these subjects and this suggestion cannot be confirmed. An alteration of the flow pattern of this type has been reported in asthma and in emphysema (Silverman, 1946), and it is possible that emphysema is responsible for the alterations in work, and the inferred alteration in flow pattern, in elderly faceworkers without pneumoconiosis and in those with P.M.F. Thus the conclusions of this investigation are not inconsistent with the suggestion of Carpenter et al. (1956) that the ventilatory capacity is low in miners without pneumoconiosis because they suffer from emphysema; it is implied that the same defect is also present in P.M.F.

\section{Conclusions}

This investigation has confirmed that P.M.F. is accompanied by a significant reduction in ventilatory ability, and that coal miners without radiological pneumoconiosis are similarly handicapped when compared with non-miners. In minor degrees of simple pneumoconiosis, however, there is no restriction of ventilation.

In accord with this the lungs were found to be stiffer than normal in P.M.F. and in elderly miners without pneumoconiosis. They were also slightly stiffer than normal in simple pneumoconiosis. It is felt that this stiffening of the lungs is not due directly to radiological pneumoconiosis but is brought on by long years of work underground. The deviation from normality was so small that this stiffening by itself is not considered to be of any clinical significance. It is not the cause of the reduction of ventilatory ability in these men, there being no demonstrable association between stiffness of the lungs and maximum voluntary ventilation.

In most of the men who have reduced powers of ventilation this is due to obstruction of the airways. This obstruction is seldom present during a normal inspiration but develops during the later stages of expiration (Fig. 1).

In some cases the reduction of M.V.V. cannot be explained in this way. It appears to be due to excessive stiffness of the chest wall. This occurs particularly frequently in elderly coal-miners without pneumoconiosis and in P.M.F. It may be the result of the distortion of the chest wall which accompanies emphysema. The results of the other tests are also consistent with the presence of emphysema in all those men who have a reduction of ventilator $y$ ability, whether pneumoconiosis can be demonstrated on the radiograph or not.

I wish to express my thanks to Professor R. C. Browne for permission to examine his patients, and for encouragement and advice. I also wish to thank Mr. D. J. Newell for the statistical analyses, Mrs. D. Weightman for the preparation of the figures, the National Coal Board for financial assistance, and Mr. E. Richardson who designed and built some of the apparatus.

\section{REFERENCES}

Attinger, E. O., Goldstein. M. M., and Segal, M. S. (1956). Amer. Rev. Tuberc.. 74, 210.

Bondurant. S., Hickam, J. B., and Isley, J. K. (1957). J. clin. Invest. $36,59$.

Butler, J. (1957). Personal communication. and Smith, B. H. (1957). Clin. Sci., 16, 125.

-, White, H. C., and Arnott, W. M. (1957). Clin. Sci., 16, 709.

Carpenter, R. G., Cochrane, A. L., Gilson, J. C., and Higgins, I. T. T. (1956). Brit. J. industr. Med., 13, 166.

Cherniack, R. M. (1956). J. clin. Invest., 35, 394

Dayman, H. (1951). Ibid., 30, 1175.

Dornhorst, A. C., Semple, S. J. G., and Young, I. M. (1953). Lancet. 1, 370 .

Fletcher, C. M. (1952). Proc. roy. Soc. Med., 45, 577. Mann, K. J., Davies, I., Cochrane, A. L., Gilson, J. C., and Hugh-Jones. P. (1949). J. Fac. Radiol. (Lond.), 1, 40.

Frank, N. R., Mead, J., Siebens, A. A., and Storey, C. F. (1956) J. appl. Physiol., $9,38$.

Gandevia, B. H., and Prime, F. J. (1957). Thorax, 12, 358.

Gilson, J. C., and Hugh-Jones, P. (1955). Spec. Rep. Ser. med. Res. Coun. (Lond.), No. 290 .

Higgins, I. T. T. (1958). Personal communication. Oldham, P. D., Cochrane, A. L., and Gilson, J. C. (1956). Brit. med. J., 2, 904.

Kennedy, M. C. S. (1953). Thorax, 8, 73.

Lilly, J. C. (1950). Meth. Med. Res., 2, 113

Marshall, R. (1957). Clin. Sci., 16, 507.

- and Dubois, A. B. (1956a), Ibid., 15, 161

(1956b). Ibid., 15, 473.

McCallum. R. I., and Browne, R. C. (1955). Brit. J. industr. Med.,

McIlroy, M. R., Marshall, R., and Christie, R. V. (1954). Clin. Sci.

McKerrow, C. B.. McDermott, M., Gilson, J. C., and Schilling, R. S. F. (1958). Brit. J. industr. Med., 15, 75,

Mead, J., Lindgren, I., and Gaensler, E. A. (1955). J. clin. Invest. 34, 1005.

- and Whittenberger, J. L. (1953). J. appl. Physiol. 5, 779.

Needham, C. D., Rogan, Mary C., and McDonald, I. (1954). Thorax, 9, 313 .

Newell, D. J., and Browne, R. C. (1955). J. Fac. Radiol. (Lond.), 7. Otis, A. B., Fenn, W. O., and Rahn, H. (1950). J. appl. Physiol., 2,

Silverman, L. (1946). J. industr. Hyg., 28, 183.

Stead, W. W., Fry, D. L., and Ebert, R. V.(1952). J. Lab. clin. Med.. 40, 674 . 